\title{
Global initiatives for improving quality healthcare by the Thalassaemia International Federation
}

\author{
Andreas Polynikis, ${ }^{1}$ Giangos Lavranos, ${ }^{2}$ AF Al Assaf ${ }^{3}$ \\ ${ }^{1}$ Former CEO of the Nicosia General Hospital, Former Quality Director, Cyprus Ministry of Health, \\ Nicosia, Cyprus; ${ }^{2}$ Vice-Chairperson, Assistant Professor, Public Health, School of Sciences, European \\ University, Nicosia, Cyprus; ${ }^{3}$ Executive Director AIHQ (American Institute for Healthcare Quality)
}

In today's health care arena, a number of issues are being raised that have received more attention either from the health care consumers or the media. The 1990 s can easily be dubbed the period of "performance measurement". Whether as a provider, a consumer or a purchaser, each was looking for ways to satisfy the other through measuring and reporting on care outcomes. Accountability was at stake in that period. Several third-party organizations attempted to produce certain measure to report on these care outcomes. A number of "indicators" were developed and measured and "report cards" were assembled.

All of these activities were done in the effort to measure performance. WHO organized and facilitated a number of activities related to quality assessment, performance improvement and outcome measurement. A large number of countries and institutions participated in these activities and initiatives. And at the end, all agreed there had to be an organized mechanism to account for quality, continuous measurement and improved performance in health care organizations. In order to do this, a mechanism for certification, licensure or accreditation should be put in place.

This trend continued in the 2000's and until now where performance measurements and improvement as on the top of the agenda of any healthcare organization and country healthcare system. Related to performance is accountability. In particular professional accountability both at the individual and the institutional levels became extremely important when dealing with issues related to performance.

\section{Certification and licensure}

It is very easy for a layperson to get confused with the terms and mechanisms of certification, licensure and accreditation. In general, certification, licensure and accreditation are all methods of evaluation and are also methods of assessing and rewarding organizations (and individuals) for healthcare quality. Accreditation is the only method however that requires a health care organization to comply with a rigorous set of performance standards and be subjected to a comprehensive process of self-assessment in addition to external evaluation. Both licensure and certification follow the same principle of assessment whereby an organization must demonstrate to the

\section{Correspondence: Andreas Polynikis.}

E-mail: polinik@cytanet.com.cy

This work is licensed under a Creative Commons Attribution 4.0 License (by-nc 4.0).

(C) Copyright A. Polynikis et al., 2018

Licensee PAGEPress, Italy

Thalassemia Reports 2018; 8:7486

doi:10.4081/thal.2018.7486 granting agency its capability and proof that it has met the standards prescribed by that granting agency, at least at the minimum levels. The difference between the three is therefore based on the rigor of the assessment process and whether the evaluation is comprehensive to all aspects of the organization. It is believed that in the case of accreditation, the process and the standards are more rigorous and more comprehensive in nature.

Therefore, certification can be defined as a process of assessing the degree by which a facility, product, unit or professional attains minimum standards. It is specific to the nature of the assessment, and the entity is "certified" as a special agency for the purpose of providing a specific service or activity.

Licensure is somewhat more similar to certification than accreditation. Again it is targeted at all entities, individuals, organizations or groups. Licensure can therefore be similarly defined as the process of assessing the extent that a facility, organization, or professional has attained minimum requirements. Unlike certification, however, without a license, an entity is prohibited from practicing the activity for which a license is needed. Therefore licensure is usually a government-sponsored activity that is put in place to control the practice of a profession or an act that has the potential of risk to the recipient or the beneficiary.

\section{What is accreditation?}

Accreditation is a rigorous and comprehensive evaluation process through which an external accrediting body assesses the quality of the key systems and processes that make up a health care organization and is applied primarily to organizations rather than individuals, departments or units.

Accreditation was developed in response to the need for standardized, objective information about the quality of health care organizations. Organizations seek accreditation for different reasons but most do so in an effort to increase market share and to win customer satisfaction and professional reputation.

The International Society of Quality in Health Care (1998) defines accreditation as: “...self-assessment and external peer review process used by health care organizations to accurately assess their level of performance in relation to established standards and to implement ways to continuously improve the health care system. Quality standards and the external peer review process are directed by nationally recognized autonomous, independent accrediting agencies with a commitment to improve the quality of health care for the public".

\section{Why accreditation?}

For more than four decades, accreditation has been the highest form of public recognition a health care organization could receive for the quality of care it provides. Accreditation offers quantitative as well as intangible benefits to a health care organi- 
zation besides public recognition. Accreditation can actually enhance the organization's strategic management decision-making process (AAAHC, 2013).

The purpose of accreditation can be summarized into the following categories:

1. Demand of the customer

2. A forum for measuring performance

3. Standardization and variance control

4. Benchmarking

5. Report cards

6. Quality improvement

7. Positive competition

8. Reward and recognition

9. Efficiency

10. Effectiveness

The above reasons are making accreditation an important process to adopt by a country and by organizations to seek:

Health care consumers are becoming increasingly aware of the different requirements a health care organization must meet in order to be considered a quality organization. They are also becoming interested in learning about the status of care provided by an organization judged by its peers or professional experts.

Accreditation provides just the answers and the assurances that health consumers are asking for. Accreditation provides for a mechanism for an objective unbiased peer review of a health organization. It provides the consumer a set of measures by which they can judge a health care organization in comparison with similar organizations.

Accreditation standards are developed to be as quantifiable as possible. Each standard is further stated in the form that will allow its measurement. Such measurable forms of the standards are often called indicators or depending on the accrediting organization may be referred to as measurable elements, evidences of performance or the like.

These standards follow the various functions and units health care organizations perform and possess. Standards are developed and are updated annually by a group of experts that are related directly to the process of care and to the structure of services rendered by the health care organization.

Compliance with these standards is a proxy measure of the performance of such an organization. Of course compliance may have to be substantial for the health care organization to receive the seal of approval from the accrediting organization. In this way accreditation can work as a measure of the performance of the organization, especially in such areas as structure and process.

One of the main activities of accreditation is to set standards that a health care organization must meet. Experts usually rigorously develop these standards. It is with these standards that the accreditation agency is able to measure the quality of the health care organization they want to evaluate for accreditation. Therefore, these standards soon become the yardsticks by which performance is measured and accreditation is achieved. Standardization is important in order that objectivity can be assured in the evaluation process. It is also a mechanism for controlling outcomes and comparing performances.

Meeting certain standards will render the health care organization "accreditable" and will decrease variation between its current performance and the desired one. Standardization is also useful in controlling cost by controlling expectations, predicting outcomes and facilitating effective budgeting.

Benchmarking and report card capabilities are two of the reasons why health care organizations should seek accreditation. These are also reasons why accreditation should be developed in order for organizations to be compared with one another based on the findings of accreditation.
Benchmarking is a process of identifying the best process, activity or outcome and to find ways to study them and emulate them in one's own setting. Through the process of accreditation, health care organizations are encouraged to look for the best processes of other organizations in order to study these processes and learn about performing them so that they can be imported and implemented in that organization.

Benchmarking is usually enhanced by the fact that most quality organizations are accredited. Similarly, one of the reasons for accreditation is to list on the health care organization's report card (outcome measures) that they are accredited. A report card is a document or report that shows a list of performance measures of that organization used primarily for positive marketing (self-generated and designed report cards) or for comparing organizations between one another using a set of measures that common to all (regulatorinduced report cards).

Health Care organizations that do not have accreditation listed on their report cards do not show complete and certainly not credible report cards. Therefore, organizations must seek accreditation and attain it in order for them to list it on their report card both for marketing and comparison objectives.

According to the quality improvement cycle shown below, accreditation is involved in all of the steps of the cycle, including quality improvement. The process of accreditation emphasizes assessment but it also encourages improvement based on the outcome of such assessment. It also encourages organizations to initiate improvement projects.

Most of the new accreditation standards call for health care organizations to demonstrate their capabilities of identifying improvement opportunities and initiating processes for improvement and development. Accreditation agencies respond positively to those organizations that demonstrate their experience in "closing the loop" from the identification and analyses of improvement opportunities to selection and implementation of actual improvements and then maintaining and sustaining that improvement. Therefore, accreditation will stimulate improvement efforts in health care organizations and will bring these organizations to a higher level of accountability.

Accreditation provides a mechanism for comparison between health care organizations. Those organizations that have achieved accreditation, especially "commendation" or "excellent" status, will have a positive image and will use that distinction to market their services accordingly. Accreditation can therefore be used as a tool for positive marketing and as a tool that enhances positive competition between health care organizations. Competition can be based on price or other factors. Competition based on quality as exemplified by the attainment of accreditation is a form of nonprice competition and is a form of positive competition. This type of accreditation is in contrast with the type of competition exhibited by and between political candidates where they each try to find weaknesses in each other performance or character to attack.

\section{Components of accreditation}

A typical system of accreditation (as seen below) is organized around four different components: administration, standards, communication and education, and surveying.

\section{The board}

Most accreditation agencies are organized as independent private entities (some with government mandate and other are actually governmental agencies) that are usually not-for-profit. Of course such a system must have credibility, and this is usually attained 
through an upper management structure such as a board of directors or a governing board. Accreditation agencies are structured in such a way to provide market representation, credibility and authority. They are also organized for the purpose of enhancing performance of health care organizations in that country or internationally. To achieve this status, most agencies have a "supervisory" board of directors or board of trustees. This board is usually made up of a mix of healthcare professionals, health industry representatives and prominent community leaders. Therefore it will consist of representatives of all of the major players in the health care system including representatives from both the government and the private sector. Professional organizations and societies may also be included on such a board. As an example one accrediting agency in the US has on its board representatives of the American Hospital Association, The American Medical Association, the American College of Surgeons, and the American College of Physicians. Sometimes prominent leaders from the community may be asked to serve on an accreditation boards of directors that may not even have any link to health care to give such board a broad representation of the professional and lay communities.

Whoever the board members are, the roles and responsibilities of such a unit is to provide oversight of the activities of the accrediting organizations. Therefore they are responsible for setting the agency's strategy, approve its overall policies and procedures, its operational plans, and the appointment of the agency's top administrator or CEO. Of course the main function of this board besides the above is to confirm and manage the award of accreditation decision of the surveyed health care organization. Therefore this board is responsible for: - Evaluation of surveyors' recommendations - Verification of information provided by the survey process - The accreditation award decision $•$ The appeal process $\bullet$ Re-evaluation and periodic surveys $\bullet$ Re-accreditation $\bullet$ Accreditation violations including suspensions and abrogation.

\section{Administration}

The accrediting organization will have an administration. This component will have a number of activities and functions that are supportive and somewhat facilitative in nature. This component is usually responsible for providing leadership and administrative to the accreditation process. Specific functions include: - Managing the day-to-day activities of the accrediting agency $\bullet$ Facilitating the application process $\bullet$ Collecting of the application and survey fees - Scheduling of the on-site survey - Identification and contact of surveyors - Travel arrangements of surveyors - Secretarial and clerical support. $\bullet$ Help desk/customer service, etc. $\bullet$ Responding to health organizations' inquiries and - Managing communications with external bodies and regulators.

\section{Education and communication}

The second component of the accrediting organization is education and communication. This component is primarily responsible for increasing awareness of the target organizations and their employees of the process and the standards of accreditation. Specifically, this component is responsible for: - Seminars/workshops - Conferences - Consultations and advice Newsletters Web-site $\bullet$ Direct mailings $\bullet$ News releases $\bullet$ Marketing.

\section{Standards}

The third component is related to the setting and continuously updating the accreditation standards and the scoring guidelines for measuring compliance to the standards. Specifically, this component will be responsible for: $\bullet$ Organizing the domains or chapters/sections for the standards manual - Developing and setting the accreditation standards and their measures $\bullet$ Identifying the documentation requirements for evaluating compliance $\bullet$ Establishing scoring guidelines • Organizing and updating the standards manuals in general.

\section{Surveying}

The fifth component of the accreditation organization is probably the most important; where the actual assessment of the health care organization is handled. Professionals working for this component will be responsible for: - Identification and Selection of surveyors - Training and orientation of surveyors - Teaming and scheduling of surveyors/facilities $\bullet$ The organizing of the site visit - Managing the survey report and the score card - Managing the surveyors' recommendations.

\section{The accreditation core standards}

Depending on the accrediting organization's emphasis, the areas for the development of standards may be different from one another. Also, the type of facility to be accredited has an effect on the type and the "domains" of standards to be developed by the accrediting organization. The following are three examples of standards chapters or domains for three different health care organizations; hospitals, ambulatory care organizations and health maintenance organizations.

\section{What will be the structure of the TIF accreditation program?}

TIF has a unique opportunity in helping its many members improve their performance and achieve international status. The accreditation program will meet this objective. The program could be housed at TIF as a separate program but under the same umbrella of TIF.

The program will have different components and functions and will serve as the accreditation "agency" for TIF member organizations seeking to enhance their performance and status among other similar organizations globally.

Similar to ISQua's International Accreditation Program, TIF's accreditation program will have a similar organizational structure and functions. The program however will have to have its own board, human resources and separate budget.

\section{The main functions of the accreditation program}

- Create and maintain the register of accredited organizations and the register of accreditation personnel;

- Represents TIF and will be participating in all relevant international, European and regional organization and meetings on accreditation;

- Draft and execute related international and national agreements on cooperation and mutual recognition of accreditation

- Seek, achieve and comply with international accreditation standards (e.g. ISQua) and become an accredited organization for the granting of accreditation of other organizations.

- Develop and deliver training of accreditation personnel and empower them to carry out accreditation activities according to the set requirements;

- Provide educational and awareness material to providers and the public on issues related to accreditation and the associated standards.

- Develop and regularly update the pertinent accreditation standards for the different member organizations globally. 
- Assess compliance of member organizations to accreditation standards through periodic site visits and periodic as needed other surveys to sustain such conformity to the standards.

- Make decisions as to the degree of compliance of healthcare organizations to the accreditation standards and decide on the awards of accreditation to such facilities or the revocation of such awards for non-complying organizations

- Develop policies, procedure and related guidelines on the preparation for site visits and the delivery of such visits to healthcare organizations nation-wide

- Develop guidelines and train surveyors on the on-site survey methodology and procedures of conducting the site visits and scoring of the standards and on reporting of the findings.

- Assess and collect surveying fees and related financial requirements to operate and sustain an effective and objective national accreditation program

- Create technical accreditation committees and approval of their provisions;

- Provide a set of guidelines and policies on accreditation decisions appeals and grievance procedures.

- Organize and deliver seminars, webinars, workshops and training venues on the accreditation standards to healthcare professionals and their organizations

- Organize and administer an annual consensus international conference on accreditation process, standards and related outcomes

- Provide an international "help-line" and mechanism to provide logistical and expert support to member organizations as they prepare for their accreditation award

- Provide comparative information to select national regulatory agencies and the public on member organizations' performance and patient related outcomes

- Assist in enhancing global awareness on patient rights and safety and on providers' responsibilities and ethical behavior

A typical system of accreditation (Figure 1) is organized around four different components: administration, standards, communication and education, and surveying.

\section{The board}

Some of the board's functions are:

- Approval of accreditation related policies and procedures developed by the accrediting body as well all operational plans of the program and its strategic plan

\section{Typical Accreditation Program} Structure

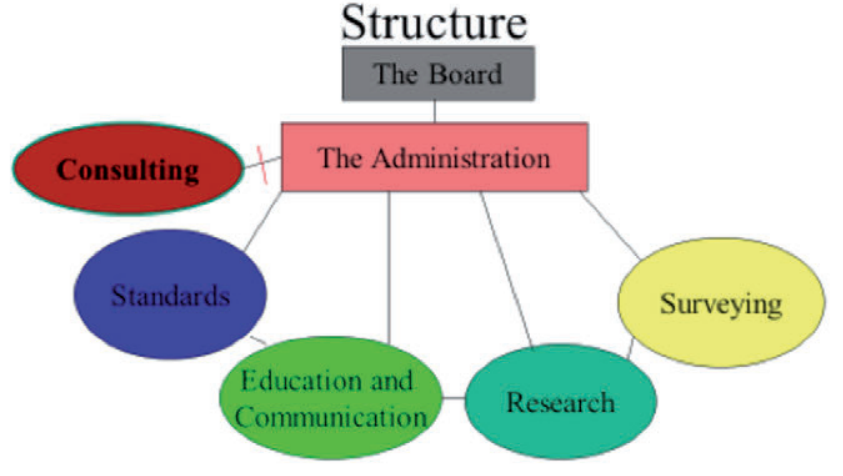

Figure 1.
- Provide oversight and overall supervision of all activities related to accreditation including the development of standards, the surveying the healthcare organizations and the education and training for healthcare professionals.

- Overseeing all budgetary and financial transactions affecting the accrediting body and their activities to collect fees and enhancing its financial stability

- Address any and all accreditation violations including suspensions and abrogation of accreditation.

\section{The administration (operation unit)}

Some of the functions include:

- Implement and maintain the overall accreditation program including all planning, financial and accounting activities.

- Manage all internal communication systems including IT, telephone, and website services of the accreditation program.

- Develop, control and regularly update management system documents including all internal policies and procedures and supportive documents for the operation of the accreditation program.

- Manage the scheduling of the on-site survey,

- Identify and contact of appropriate surveyors for the survey visit taking in consideration issues related to availability, logistics, and conflicts of interest

- Coordinate travel arrangements of surveyors and the processing of travel related expenses and reimbursements

- Provide relevant secretarial and clerical support to the accreditation staff, surveyors and sometimes to member organization as needed and seen appropriate.

- Maintain personnel files and the human resources management of accreditation organization/center

\section{Awareness, education, and communication}

This component may be responsible for:

The organization and delivery of seminars/workshops on the accreditation standards including the development of curricula, the identification of the instructors/trainers, the development of the training material, the marketing and solicitation of the events as well as the selection and logistical support at the venues

- The organization and administration of accreditation related international conferences and gatherings

- The marketing and deliver of focused consultations and advice to interested healthcare organizations on issues related to accreditation, the standards and how to comply with them

\section{Standards}

This component may be responsible for;

- Organizing the domains or chapters/sections for the standards manual

- Developing and setting the accreditation standards and their measures

\section{Surveying and external monitoring}

The fifth component may be responsible for:

- Identification and Selection of potential surveyors recruited or nominated from different member organizations internationally. Training and orientation of candidate surveyors and the retraining of established and seasoned surveyors

- Managing the surveyors' recommendations including their distribution to the Board and later with healthcare organization Developing the national database for required performance measures and the publishing of periodic benchmarking, individualized and comparison reports for healthcare organizations 


\section{Legal compliance and appeals}

This unit may be responsible for:

- Provision of a Commission on Appeals by establishing main policies and procedures for consideration of appeals of against decisions, actions and inactions of the accreditation agency including its survey findings and accreditation decisions and commissioning specific actions regarding appeals

- Responsible for responding to any legal matters and law related issues and inquiries including any court related actions and proceedings that may arise and affect any of the staff of the accreditation organization during their official operation and duties.

\section{Challenges of the TIF accreditation program}

Although accreditation has many advantages as outlines earlier, there are some challenges that need to be addressed here.

1. Resources. Identifying new and suitable resources to start the program is the most challenging action. Not only new funds are needed but also identifying the right individuals to provide the support and sustainability needed for the program. There are expenses for consultants and expenses for documentation and related material development including standards, guidelines, policies and measures. Then there are expenses for training, marketing and winning buy-ins from member organizations for the program to sustain and succeed.

2. Buy-ins. Certainly, this issue is the most challenging. Trying to get members to first accept the program then subscribe to it and sustain it will not be that easy to achieve. Nevertheless, these challenges and similar others are achievable and will be fruitful in the long run. Patience on the part of TIF and its constituents is the key to achieve the objective of accountability.

3. Organization and administration. As mentioned earlier identifying the right personnel to advice, support and administer the program will not be that easy. Not every good professional is one that can help with accreditation. There is a need for highly qualified and trained individuals to establish and continue to sustain the program. Additionally, besides human resources, there is the need to develop all the material for the program from job descriptions, to standards, to surveyor guidelines, to training material to policies etc.

4. Time and results. This is a long process and will require many months to build the program at least on paper, then get the necessary approvals from TIF constituents, get buy-ins and subscribers, and then launch it globally.

\section{Program participation}

In order to make the program sustainable at least for the first few years of operation, the Accreditation program should become mandatory for TIF's member organizations. Existing organizations will be given up to 3 years to get accredited but should start preparing for it right away. For new programs, they should be given up to 18 months to achieve accreditation once they become operational. Mandatory accreditation will insure maximum participation and will help sustain the program. Bit more importantly it will put all member organizations at a similar level of performance and would share the same operational standards thus improving their processes and outcomes. Additionally, mandatory accreditation will generate the needed additional resources to sustain the program and make continuous improvement for TIF and its members.

The challenge is how can you make that decision and achieve full buy-ins and active participation from all members. With adequate marketing, strong messages, and getting the Board's support will all help achieve that goal. This decision will not be considered until the accreditation program is built and all required documentations are developed. Certainly a credible consultant will be instrumental is assisting TIF complete this task.

\section{References}

1. AAAHC (2014). The Accreditation Association for Ambulatory Health Care, Washington, DC. http://www.aaahc.org.

2. CCHSA (2014). Canadian Council on Health Services Accreditation, Ottawa, Ontario, Canada. http://www.accreditation.ca/

3. CMS (2014). The Centres for Medicare and Medicaid Managed Care, Rockville, Maryland. http://www.cms.gov

4. International Organization for Standardization. "Overview of the ISO System.” Geneva, Switzerland, 2014. http://www.iso.org

5. ISQua (2014). International Society for Quality in Healthcare, Victoria, Australia. http://www.isqua.org

6. JCI. Joint Commission International Accreditation Survey Process Guide for Hospitals. Oakbrook Terrace, Illinois: Joint Commission on Accreditation of Healthcare Organizations, http://www.jointcommissioninternational.org/

7. Joint Commission Resources. "Accreditation Overview." Oak Brook, Illinois: Joint Commission Resources, Inc., 2014.

8. NCQA (2014). The National Committee on Quality Assurance, Washington, DC. http://www.ncqa.org.

9. Simmons, D. "Examining ISO 9000 in Health Care." Quality Digest, March 1998.

10. URAC (2014). American Accreditation HealthCare Commission, Washington, DC. http://www.urac.org.

11. VanOstenberg, P. "Joint Commission International (JCI): A Partner in Quality and Safety." Joint Commission Journal on Quality and Safety, 2004 Global Supplement, 2004, pp 5-8.

12. WHO/EMRO (1999). Intercountry consultation on accreditation of district health facilities, Limasol, Cyprus EMR/ $\mathrm{HSD} / 200$.

13. WHO/SEARO (1998). Intercountry meeting on accreditation, Surabaya, Indonesia SEA/HSD/200 